\title{
ИНТЕГРАЦИЯ ИННОВАЦИОННЫХ ТЕХНОЛОГИЙ В ОСНОВНЫЕ СЕГМЕНТЫ ТУРИСТСКОЙ ИНДУСТРИИ
}

\author{
Н. В. Белоусова \\ Национальный авиачионный университет, Украина \\ Поступила в редакиию 24 апреля 2019 г.
}

\begin{abstract}
Аннотация: Представлены результаты исследования уровня внедрения и использования инновационных технологий в туристской сфере. Рассмотрен понятийно-терминологический аппарат, а также дискуссионные вопросы касательно употребления и интерпретации понятий «виртуальный туризм», «виртуальная экскурсия», «аутсорсинг». Предложена характеристика наиболее известных инноваций в ресторанном, отельном и информационном сегментах туристской индустрии. Определены факторы и причины, влияющие на развитие инновационных технологий в туризме.
\end{abstract}

Ключевые слова: инновационные технологии, виртуальный туризм, виртуальные экскурсии, туристская сфера, интернет-услуги.

Integration of innovative technologies in the main segments of the tourism industry

\section{N.V. Belousova}

Abstract: The results of the study of the level of implementation and use of innovative technologies in the tourism sector are presented. The conceptual and terminological apparatus, as well as discussion questions regarding the use and interpretation of the concepts of «vertical tourism», «vertical tour», and «outsourcing» are considered. The characteristic of the most famous innovations in the restaurant, hotel and information segments of the tourism industry has been proposed. The factors and causes affecting the development of innovative technologies in tourism are identified.

Key words: innovative technologies, virtual tourism, virtual excursions, tourism, Internet services.

Внедрение современных инновационных и доступных технологий с последующим рациональным использованием их в практической деятельности является приоритетной задачей сферы туризма, а сам туризм представляется нам идеальной экспериментальной площадкой для применения и адаптации инновационных технологий.

Сегодня инновационную модель в туризме рассматривают как совокупность взаимосвязанных и взаимодополняющих элементов, главными из которых являются: система продуцирования научных знаний и инноваций, система коммерциализации научных знаний и инноваций, система управления и регулирования инновационным развитием. Успех внедрения инновационной модели развития туристской сферы в полном объеме зависит от гармоничной и комплексной взаимосвязи всех вышеперечисленных составляющих.

(C) Белоусова Н.В., 2019

(c) (i) Материал статьи доступен по лицензии Creative Commons "Attribution" 4.0
Для понимания уровня использования инновационных методов, приемов, технологий туристской деятельности необходим мониторинг наиболее популярных и востребованных сфер. В данной статье мы попытались унифицировать научные исследования и практические результаты по вопросам разностороннего применения инноваций в туристской индустрии с анализом наиболее перспективных технологий, которые уже внедряются в туризме, и очертить круг проблем, которые требуют глубокого научного изучения и перспективных шагов реализации.

Поэтому цель данной статьи - определение современных тенденций применения инновационных технологий в туристической сфере, анализ проблем и разработка перспектив для дальнейшей реализации инноваций.

\section{ОБЪЕКТЫ И МЕТОДЫ ИССЛЕДОВАНИЙ}

Актуальность всестороннего исследования, поиск и внедрение инноваций в туризм обусловлена многогранностью и общественной значимо- 
Вариации научного обоснования понятия «инновации в туризме»

\begin{tabular}{|l|l|}
\hline \multicolumn{1}{|c|}{ Aвтор } & \multicolumn{1}{|c|}{ Научное обоснование понятия автором } \\
\hline Власова Н., & \multicolumn{1}{|c|}{$\begin{array}{l}\text { Инновации и туризме - это системные меры, имеющие качественную } \\
\text { Семененко Н., } \\
\text { новизну и приводящие к позитивным сдвигам, обеспечивающих устойчивое } \\
\text { функционирование и развитие отрасли в регионе. }\end{array}$} \\
\hline Тайгибова Т. & $\begin{array}{l}\text { Инновации и туризме - системные мероприятия, имеющие качественную } \\
\text { новизну и приводят к положительным сдвигам, что обеспечивает устойчивое } \\
\text { функционирование и развитие отрасли в регионе. }\end{array}$ \\
\hline Маклашина Л. & $\begin{array}{l}\text { Инновации и туризме - разработка, создание новых туристских маршрутов, } \\
\text { проектов и т.д. с применением науки, техники, IТ-технологий, а также } \\
\text { передового опыта в области управления и маркетинга, внедрение которых } \\
\text { позволит повысить уровень занятости населения, обеспечить рост его } \\
\text { доходов, ускорить социально-экономическое развитие и улучшить } \\
\text { туристский имидж страны и регионов. }\end{array}$ \\
\hline Новиков В. & $\begin{array}{l}\text { Инновации и туризме - результат действий, направленный на создание } \\
\text { нового или изменение существующего туристского продукта, освоение } \\
\text { новых рынков, использование передовых информационных и } \\
\text { телекоммуникационных технологий, совершенствование туристических, } \\
\text { транспортных и гостиничных услуг, создание стратегических альянсов для } \\
\text { осуществления туристского бизнеса, внедрение современных форм } \\
\text { организационно-управленческой деятельности туристских предприятий. }\end{array}$ \\
\hline
\end{tabular}

стью туристской индустрии, а также высокой конкуренцией на рынке.

Общие вопросы исследования направлений развития и внедрение инновационных технологий в туризме рассматривают такие ученые, как М. Ю. Кизимова, М. И. Рутинский, М. Бойко, А. А. Киндры, Ф.А. Нагорный, Р. А. Максимов, М. Х. Заболотный, Х. Р. Колотухин, М. В. Кощуба, Х. С. Ратушняк, Д. И. Прокопенко. Тем не менее, в их научных трудах недостаточно полно раскрыты вопросы создания и использования системы инновационного менеджмента на туристских предприятиях.

В условиях динамичного развития новейших технологий, решение проблемы поиска и оптимального использования инноваций в разных сферах человеческой деятельности, в том числе туристской, основывается на формировании рыночных структур на основе комплексно-пропорциональной организации индустрии туризма, проведения согласованной туристской политики, изучении туристского спроса, применении концепций маркетинга в туризме.

Рассматривая инновацию как новый продукт, новое явление или действие на рынке (предприятии), мы имеем в виду процесс привлечения потребителя, удовлетворение его потребностей и одновременно обеспечение дохода предпринимателю. Кроме того, инновационная деятельность традиционно представляются как показатель научно-технического прогресса и как процесс, связанный с внедрением результатов научных исследований и разработок в практику. Однако смысл и содержание понятия «инновация» более широк (таблица) [3, с. 113-114].

Инновационный процесс включает в себя: нововведения; инновационную деятельность; государственную инновационную политику; инновационный потенциал; инновационную сферу; инновационную инфраструктуру и инновационные программы [4, с. 13].

Рассматривая совокупность всех этапов инновационной деятельности в период от поиска новых идей к их использованию, коммерциализации и распространения, рационально свести эти данные в единую систему, используя понятие «инновационный цикл» (рис. 1).

Если акцентировать внимание на степени инновационного развития туристской отрасли, то можно определить следующие составляющие: рыночная конъюнктура, уровень образования и квалификации кадров, наличие на исследуемой территории ресурсов, прежде всего уникальных ресурсов, наличие необходимой материально-технической базы, современных форм и приемов работы с клиентами. Но наиболее перспективными в современной практике туризма являются: про- 


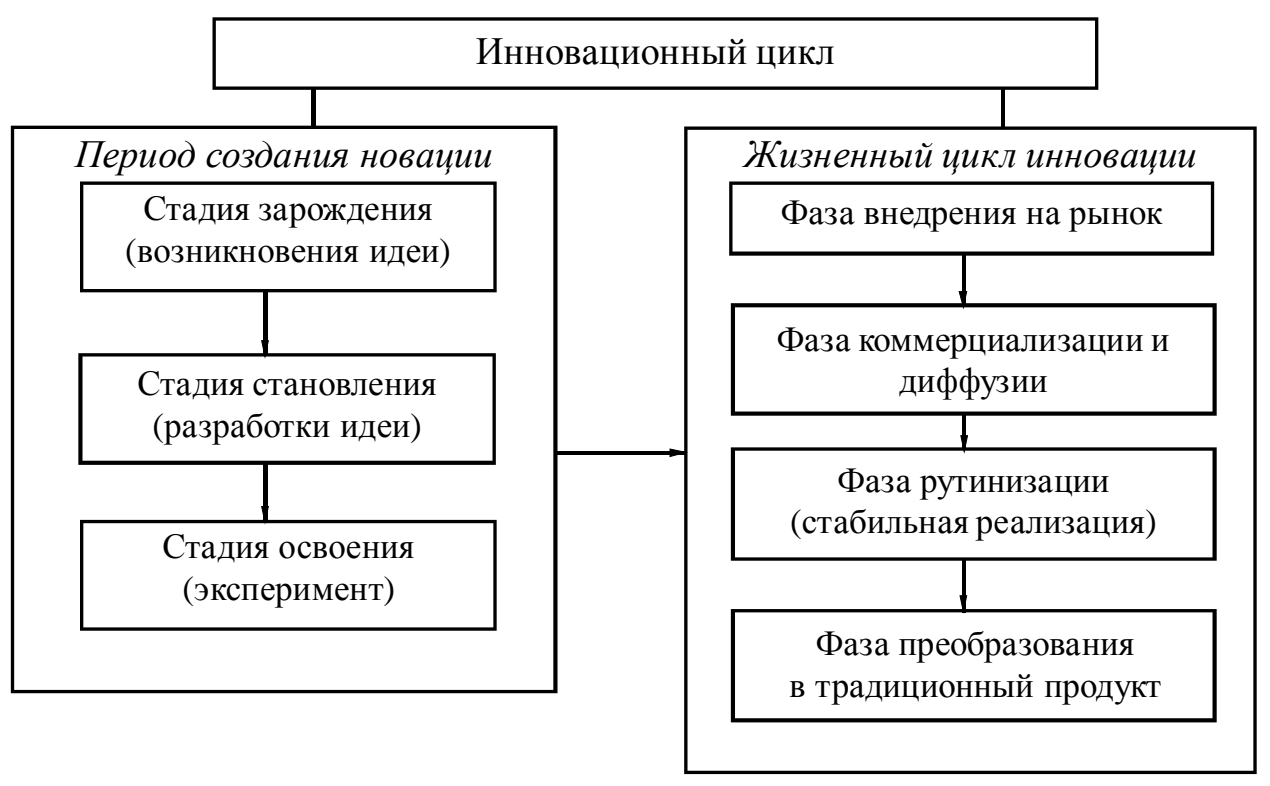

Puc. 1. Схема инновационного цикла

дуктовые, технологические, маркетинговые, сервисные и организационно-управленческие [7, с. 147-155].

Изучение тенденций и закономерностей комплексного освоения инноваций, планирование положительных результатов и управление ими сложная методологическая проблема в сфере туризма, связанная, прежде всего, с классификацией нововведений, в том числе, с определенными классификационными признаками (рис. 2).

Инновации в туризме следует рассматривать как идею создания и реализация туристских проектов, даже не приносящих вначале существенной прибыли, может дать толчок развитию туризма и тем самым активно способствовать созданию дополнительных рабочих мест и росту доходов населения.

На практику нового туризма влияют такие факторы, как демографические изменения (старение населения), стиль жизни, характер работы, частота и продолжительность отпусков, появление новых материалов для одежды и обуви, которые стали материальной основой экстремального туризма, способствовали развитию водного, горного и ряда других видов туризма. Совершенствуются транспортные, гостиничные и другие услуги, осваиваются новые рынки, внедряются современные формы организационно-управленческой деятельности.

Трансформации, которые произошли в мировой экономике на протяжении последних десятилетий, привнесли существенные изменения в туристскую инфраструктуру. Достаточно проанализировать тенденцию внедрения инноваций в виде интернет обслуживания интернет-услуг, он-лайн- заказов, виртуальное знакомство с экскурсионными объектами с помощью QR-кодов, применение 3D моделирования, бум в ресторанном бизнесе за счет инновационных предложений органической кухни и т.д.

Бурное развитие сети Internet - от текстовой передачи данных к мощному мультимедийному способу общения, стал источником новых современных возможностей в туристской отрасли.

Виртуальность, как инновационный процесс, ассоциируют с моделированием с помощью компьютера в виде он-лайн или офф-лайн презентаций, которые позволяют потенциальным клиентам рассмотреть любой туристский объект в виде широкоформатных или панорамных слайдов разных размеров [6].

Таким образом, инновационная деятельность в сфере туризма создает предпосылки для совершенствования транспортных, гостиничных и других услуг, освоение новых рынков, внедрение передовых информационных и телекоммуникационных технологий, а так же современных форм в организационно-управленческую деятельность туристской индустрии.

\section{РЕЗУЛЬТАТЫ ИССЛЕДОВАНИЯ И ОБСУЖДЕНИЕ}

Учитывая полифункциональность туристского сегмента, мы предлагаем рассмотреть инновационные технологии в рамках работы гостинично-ресторанного комплекса, рекламно-информационной модернизации, интернет-ресурсного поля, туристских дестинаций и других составляющих данной отрасли. 


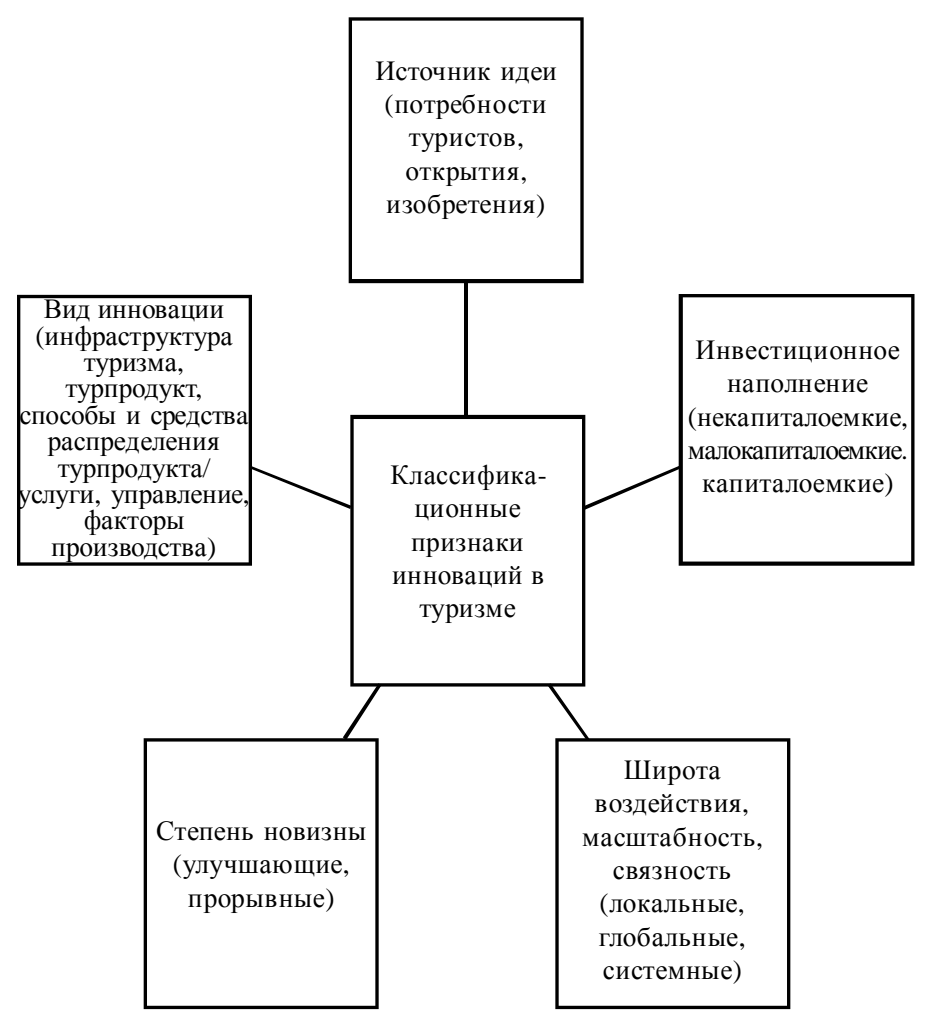

Puc. 2. Классификационные признаки инноваций в туризме [8]

Инновационная стратегия на уровне предприятия гостиничного хозяйства представляет собой комплекс мероприятий по определению наиболее важных направлений, выбор приоритетов эффективного развития данной индустрии, повышение уровня конкуренции на рынке туристских услуг. При этом, главным условием развития гостиничного предприятия является постоянная модернизация материально-технической базы, согласно новейшим разработкам и технологиям: оснащение номеров Wi-Fi и дистанционным управлением бытовых опций номера, наличие интернет-услуг, предоставление отельных услуг для инклюзивных туристов, имеющих инвалидность разных нозологий (особенно для колясочников) и т.д.

Анализируя ситуацию в туристской индустрии в странах постсоветского пространства в целом и состояние гостиничных предприятий в частности, необходимо отметить следующие моменты, препятствующие быстрому инновационному развитию: 1) доминирование в гостиничных комплексах устаревшей материально-технической базы; 2) низкий профессиональный уровень обслуживающего персонала гостиниц (часто отсутствует подбор кадров по узкопрофильной туристской специализации); 3) низкий уровень обслуживания иностранных гостей работниками гостиниц (не знание иностранных языков, обычаев, традиционных приветствий, национальных особенностей и т.д.); 4) слабое экскурсионное обслуживание (экскурсии часто проводят историки, краеведы и другие работники смежных направлений, но не специалисты туристской сферы, которые имеют четкое представление о специфике и методике предоставления такого рода услуг); 5) практически полное отсутствие специализированного транспорта для инклюзивных туристов, в том числе людей с инвалидностью, что снижает конкурентоспособность туристского сегмента и способствует оттоку достаточно большой социальной группы перспективных туристов.

Эффективное решение существующих проблем (рис. 3) позволит создать новую модель роста туризма, в центре которой будет совершенствование материально-технической базы и внедрения в сферу туризма новой техники и технологий, обеспечивая тем самым эффективную рекламу турпродукта, транспортную доступность туристских центров и создание высококвалифицированного персонала, способного предложить качественное обслуживание.

Если раньше гостиничная сфера была ориентирована преимущественно на туристов, которые «диктовали» гостиницам условия работы, то сегодня ставка часто делается на представителей биз- 


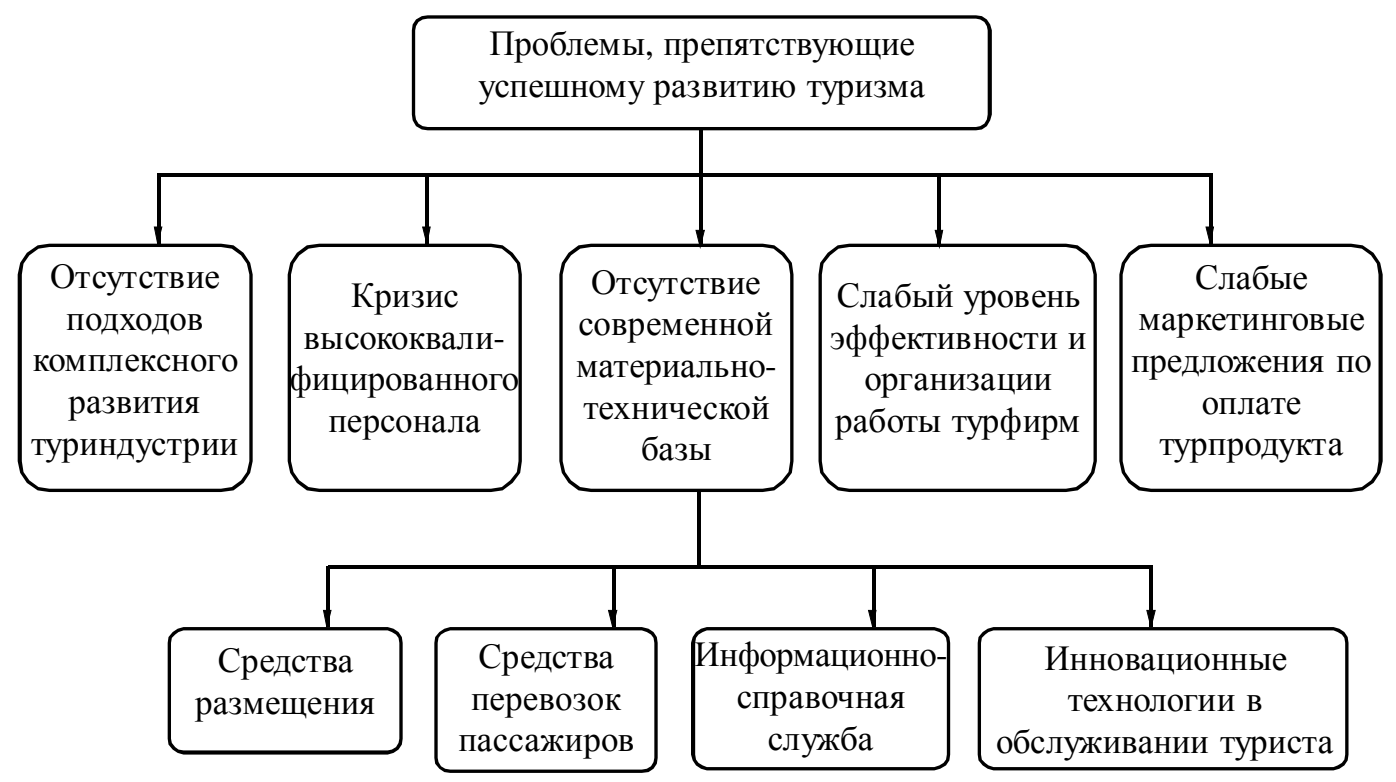

Puc. 3. Проблемы, препятствующие успешному развитию туризма

неса: организация конгрессов, предоставление залов для пресс-конференций или организации переговоров с клиентами и партнерами, для которых, в качестве новых опций, предлагают услуги фитнес-центров, spa-салонов, бассейнов с разной температурой, диетическое меню в ресторанах, расселения клиентов по национальному признаку, по температурному режиму номера, особенностям меблировки, наличию тех или иных предметов интерьеpa, которые соответствуют культуре гостя, возможности выбора блюд из меню, соответствующим или очень близким к национальной кухни гостя.

Безусловной изюминкой в деятельности гостиничного бизнеса является появление отелей с акцентом на эксклюзивность, имеющих множество удивительных особенностей: комнаты имеют не порядковую нумерацию, мебель группируется по цвету, в номерах есть собственный обслуживающий персонал, работающий только на конкретного гостя (отели Шри-Ланки, Малайзии, провинции Гоа, Доминиканской Республики и т.д.). Кроме того, в последние годы применяется инновационная технология RFID, позволяющая создавать единые платежные системы (когда турист идентифицирует себя и производит оплату за предоставленные услуги) и может определить местонахождение гостя отеля.

Неразрывно с гостиничным хозяйством рассматриваются перспективы внедрения инноваций в ресторанную сферу, когда в процессе обслуживания различных контингентов потребителей внутреннего туристского сегмента и предоставления им услуг в сфере питания становится прибыльным сектором экономики страны и выгодно позиционирует свою страну на международном рынке.

Ресторанный сегмент растет стремительнее остальных за счет того, что в последнее время для этого совпало два благоприятных фактора: предложение и спрос. Если проследить тенденции развития ресторанных предприятий, то можно обнаружить их количественное сокращение, с одной стороны, и рост гастрономических направлений, разнообразие кухни разных стран, с другой.

Например, в Украине в 2013 году эти объемы составили 24,6 млрд. гривен (примерно 1 млрд. \$), тогда как в 2008 году всего 11,7 млрд. гривен (примерно 433 млн. \$) [2]. Именно поэтому можно утверждать, что ресторанный сегмент туристской сферы имеет существенный потенциал для развития, как в качественном, так и в количественном аспекте.

Кроме того, современные тенденции управления ресторанным бизнесом позволяют использовать услуги аутсорсинга - привлечение узконаправленных профессионалов в некоторые производственные процессы: клининг, управление персоналом, приготовление отдельных (специальных) блюд и другие опции, что обеспечивает бесперебойную работу учреждения, минимизирует собственные риски, в результате выполнения задач профессионалами, дает возможность существенно экономить на фонде заработной платы и ее налогообложении.

При этом существуют некоторые риски: утечка конфиденциальной информации, разглашение коммерческой информации, что является важным 
и существенным фактором конкурентоспособности предприятия; высокие цены на стоимость услуг при отсутствии конкуренции на рынке аутсорсинговых компаний [1].

Сфера туризма идеально приспособлена для использования современных информационных технологий, которые продолжают список перспективных опций туристической сферы.

На сегодняшний день около $36 \%$ европейских туроператоров и 40 \% туристских агентств, предлагают онлайн-бронирования туров. В Европе наблюдается тенденция бронирования мест в гостиницах туристами напрямую, минуя посредников (по данным Еврокомиссии, под эту опцию адаптировано $62 \%$ европейских отелей), что позволяет сэкономить до $40 \%$ стоимости [2].

Основными способами продвижения туристского бизнеса в онлайн-режиме являются: сайт компании, e-mail маркетинг, специализированные порталы и XML экспорт, продвижение в поисковых системах, медийная реклама, контекстная реклама в результатах поиска, PR в Интернет, SMM продвижение, BTL нестандартные методы продвижения, мобильные технологии и другие.

Предлагая интерактивность, скорость и неограниченную доступность, Internet создал предпосылки для возникновения такого инновационного и парадоксального явления в туризме как «виртуальный туризм», теоретические аспекты которого пока мало исследованы в научных кругах и, как следствие, отсутствует четкое определение понятий «виртуальный туризм» и «виртуальные экскурсии», а так же не раскрыта их сущность. Нам виртуальный туризм известен в виде 3D-экскурсии, 3D-панорамы, 3D-туры.

Виртуальный туризм является парадоксальным явлением, сущность которого не соответствует стандартным общепринятым восприятиям или классической трактовке туризма и предлагается в виде пассивной формы отдыха при отсутствии необходимости изменения своей геолокации, не предусматривает реальное использование различных природных, рекреационно-туристических ресурсов и объектов историко-культурного наследия и т.д. Объединяющим звеном виртуального и реального туризма является их продолжительность - до 24 часов.

Выполнив сравнительный анализ общих и отличительных признаков традиционного туризма и виртуального, а также характерных черт классической экскурсии и виртуальной, было установлено, что более конкретное название данного инно- вационного явления является «виртуальная экскурсия». В формате 3D виртуальные экскурсии выглядят как фотореалистичные картинки для демонстрации объемного пространства и дает возможность воспринимать большой объем необходимой визуальной информации. Преимуществами виртуальных экскурсий выступают - интерактивность, создающая эффект присутствия и позволяющая пользователю не только пассивно наблюдать, но и активно участвовать в процессе; реализация потребностей в путешествиях для людей с инклюзией, особенно людей с инвалидностью и их финансовыми возможностями; информативность (а) получение полной или частичной информации о любом объекте туристской дестинации; б) детальное ознакомление с объектами, с помощью 3Dизображения); универсальность и простота в использовании, когда туры могут быть размещены на любом электронном носителе или загружены на веб-страницах для широкого и доступного использования; экономия времени и денег (традиционные путешествия требуют значительных финансовых затрат, а виртуальные - полностью бесплатные и дают возможность экономить время); безопасность в процессе «виртуального путешествия» или «виртуальной экскурсии»; достоверность и убедительность: предоставляется возможность посмотреть любой уголок геопространства в отличие от статичного фото.

К недостаткам виртуального туризма (виртуальных экскурсий) можно отнести: недостаток человеческих эмоций; низкий уровень запоминания; полноценность изображения только на электронных носителях.

\section{ВЫВОДЫ}

1. Повышение уровня простоты и доступности услуг для гостя является основным приоритетом в работе туристской сферы. На фоне галопирующего развития современных инновационных технологий, туризм, имеющий многофункциональную сегментарность своей деятельности, выступает одним из наиболее универсальных видов хозяйствования, где инновации имеют быстрое и финансово окупаемое применение.

2. Необходимым условием в достижении успеха в любом начинании является здоровая конкуренция. Туризм как наиболее многогранная и востребованная отрасль хозяйства, требует постоянной модернизации с применением современных инновационных технологий, подходов, методов, что обеспечивает не только конкурентоспособ- 
ность туристских предприятий, но и стабильность в их работе. Инновации в туризме основываются на новизне услуг, улучшении технологичности их предоставления, экономической и социальной эффективности.

3. Для успешной реализации поставленных задач, прежде всего, необходимо инвестирование в инновационную сферу туристской деятельности, создание современной высокотехнологической инфраструктуры, способной интегрироваться с предприятиями туризма разных стран, что практически невозможно без возобновления и кардинальной перезагрузки науки с дальнейшей коммерциализацией результатов полученных научных разработок.

4. Международный опыт внедрения виртуальных туров убедительно доказывает, что данное направление деятельности создает условия для повышения конкурентоспособности туристских услуг. Туристский продукт, презентованный в виде виртуального тура, имеет максимальную информационную вместительность, являясь более интересным и привлекательным продуктом туризма. Использование виртуальных 3D-экскурсий в сфере туризма имеют перспективу стать наиболее эффективным и востребованным направлением Internet-технологий для популяризации туристских объектов; популярным маркетинговым инструментом для многих учреждений гостиничного и ресторанного хозяйств, музеев и других объектов коммерческой недвижимости в индустрии туризма; эффективным инструментом визуализации туристских ресурсов для потенциальных потребителей туристских услуг; альтернативой традиционному (классическому) туризму для людей, которые не имеют физической или финансовой возможности путешествовать.

5. Электронный бизнес открывает большие возможности развития любому предприятию. Это новая форма рыночных отношений, основанная на применении новейших телекоммуникационных технологий и Интернета. Эта система торговли приемлема и для покупателя, и для продавца. Но главное, что туризм имеет важное преимущество перед другими секторами электронной торговли его потребитель получает товар непосредственно в месте его производства, в туристском центре.

6. Применение инноваций в туристской сфере направлены на формирование нового туристского продукта, предоставление уникальных туристских услуг, применения новых маркетинговых подходов, используя новейшую технику и IT-техноло- гии, что повысит конкурентоспособность туристского продукта на национальном и международном рынках, приведет к появлению новых видов туризма. Степень инновационного развития туристской отрасли определяют: рыночная конъюнктура, уровень образования и квалификации кадров, наличие на исследуемой территории ресурсов, прежде всего уникальных ресурсов.

\section{СПИСОК ЛИТЕРАТУРЫ}

1. Аутсорсинг и аутстаффинг. - URL: http:// www.horeca62.ru/articles/163-autsorsing-i-autstaffing.

2. Божук Т. И. Тенденции деятельности гостиничного хозяйства (на примере Турции и Украины) / Т. И. Божук, С. Ю. Пенкальская // Туристический и гостинично-ресторанный бизнес в Украине: проблемы развития и регулирования : материалы VII Международной научно-практической конференции. - Черкассы : Издатель Ю. А. Чабаненко, 2016. - Т. 1. - С. 17-19.

3. Власова Н. Инновационная деятельность в туристическом бизнесе / Н. Власова, В. Смирнова, Н. Семененко // Культура народов Причерноморья. - 2009. № 176. - C. 113-114.

4. Гарбер А. Е. Основные теоретические и практические аспекты инновационной деятельности в туристическом хозяйстве Украины. / А. Е. Гарбер // Инвестиции : практика и опыт. - 2009. - № 23. - С. 29-31.

5. Новиков В. С. Инновации в туризме / В. С. Новиков. - Москва : Академия, 2007. - 208 с.

6. Самохвал О. О. Виртуальная экскурсия как инновационный метод лингвострановедческой подготовки будущих специалистов туристической сферы / О. О. Самохвал, Н. В. Войнаровская // Научные записки Национального университета «Острожская академия». Сер. Филология. - 2013. - Вып. 33. - С. 312-315. - URL: http://nbuv.gov.ua/j-pdf/Nznuoaf 201333 98.Pdf.

7. Смирнов И. Г. Логистика туризма : учебное пособие / И. Г. Смирнов. - Киев : Знание, 2009. - 444 с.

8. Тайгибова Т. Т. Инновации в туризме - как один из важнейших факторов повышения уровня социально-экономического развития Республики Дагестан / Т. Т. Тайгибова // Проблемы современной экономики : материалы Международной научной конференции. Челябинск : Два комсомольца, 2011. - С. 153-156. URL: https://moluch.ru/conf/econ/archive/12/1380/ (дата обращения: 27.05.2019).

\section{REFERENCES}

1. Autsorsing $i$ autstaffing (Outsourcing and outstaffing) Available at: http://www.horeca62.ru/articles/163-autsorsing-i-autstaffing.

2. Bozhuk T. I., Penkal'skaya S. Yu., Tendentsii deyatel'nosti gostinichnogo khozyaystva (na primere Turtsii i Ukrainy) [Trends in the hotel industry (for example, Turkey and Ukraine)]. Turisticheskiy i gostinichnorestorannyy biznes $v$ Ukraine: problemy razvitiya i regu- 
lirovaniya : materialy VII Mezhdunarodnoy nauchnoprakticheskoy konferentsii (Tourism and hotel and restaurant business in Ukraine: problems of development and regulation: proceedings of the VII International Scientific and Practical Conference), Cherkassy : Izdatel' Yu. A. Chabanenko, 2016, Vol. 1, pp. 17-19.

3. Vlasova N., Smirnova V., Semenenko N., Innovatsionnaya deyatel'nost' v turisticheskom biznese [Innovation in the tourism business]. Kul'tura narodov Prichernomor'ya, 2009, No. 176, pp. 113-114.

4. Garber A. E., Osnovnye teoreticheskie i prakticheskie aspekty innovatsionnoy deyatel'nosti v turisticheskom khozyaystve Ukrainy [The main theoretical and practical aspects of innovation in the tourism industry of Ukraine]. Investitsii : praktika i opyt, 2009, No. 23, pp. 29-31.

5. Novikov V. S., Innovatsii v turizme [Innovation in tourism]. Moscov, Akademiya, 2007, 208 p.

6. Samokhval O. O., Voynarovskaya N. V., Virtual'naya ekskursiya kak innovatsionnyy metod lingvostranovedcheskoy podgotovki budushchikh spetsialistov turis-

Белоусова Наталия Владимировна

кандидат географических наук, доцент, профессор кафедры землеустройства и кадастра Национального авиационного университета, г. Киев, Украина, E-mail: belousova-69@ukr.net ticheskoy sfery [Virtual excursion as an innovative method of linguistic and regional training of future tourism specialists]. Nauchnye zapiski Natsional'nogo universiteta «Ostrozhskaya akademiya». Ser. Filologiya, 2013, Vol. 33, pp. 312-315, Available at: http://nbuv.gov.ua/j-pdf/ Nznuoaf_2013_33_98.Pdf.

7. Smirnov I. G., Logistika turizma [Tourism Logistics]. Kiev, Znanie, 2009, 444 p.

8. Taygibova T. T., Innovatsii v turizme, kak odin iz vazhneyshikh faktorov povysheniya urovnya sotsial'no-ekonomicheskogo razvitiya Respubliki Dagestan [Innovations in tourism - as one of the most important factors in increasing the level of socio-economic development of the Republic of Dagestan] Problemy sovremennoy ekonomiki : materialy Mezhdunarodnoy nauchnoy konferentsii (Problems of the modern economy: proceedings of the International Scientific Conference). Chelyabinsk, Dva komsomol'tsa, 2011, pp. 153-156, Available at: https:// moluch.ru/conf/econ/archive/12/1380/ (accessed 27 May 2019).

Belousova Natalia Vladimirovna

Candidate of Geographical Sciences, Associate Professor, Professor of the Department of Land Management and Cadastre of the National Aviation University, Kyiv, Ukraine, E-mail: belousova-69@ukr.net 